\title{
Abdominal pain leading to incidental finding of polyarteritis nodosa
}

\author{
Ella Starobinska, ${ }^{1}$ Kawanjit Sekhon, ${ }^{2}$ Jawad Bilal ${ }^{2}$
}

Internal Medicine, Banner University Medical Center, Tucson, Arizona, USA

${ }^{2}$ Internal Medicine, University of Arizona, Tucson, Arizona, USA

\section{Correspondence to}

Dr Ella Starobinska,

elstar@email.arizona.edu

Accepted 11 June 2018

\section{DESCRIPTION}

A 51-year-old man with new-onset hypertension presented with mild epigastric pain that started 3 days ago. The pain was associated with emesis, subjective fevers and diaphoresis. $\mathrm{He}$ denied haematemesis, haematochezia, melena, fatigue, night sweats, abnormal bowel movements, weight change, skin changes or neuropathy.

His vitals were significant for heart rate of 120 bpm. He appeared pale with peripheral cyanosis. Abdomen was diffusely tender with normal bowel sounds. There was no rebound tenderness. Complete blood count, comprehensive metabolic panel, amylase and lipase levels were normal. CT of the abdomen demonstrated an abdominal haematoma centred ventral to the third portion of the duodenum and bilateral renal wedge-shaped infarcts (figures 1-3). Abdominal angiogram showed irregular pancreaticoduodenal arcade with microaneurysms originating from a branch of the proximal superior mesenteric artery (figure 4). The rupture of one of the microaneurysms was presumed to be the source of the haematoma. Rheumatological work-up included erythrocyte sedimentation rate of $48 \mathrm{~mm} /$ hour (0-10 mm/hour), C-reactive protein $81.3 \mathrm{mg} / \mathrm{L} \quad(0.00-3.00 \mathrm{mg} / \mathrm{L})$, negative antinuclear antibodies and antineutrophil cytoplasmic antibodies. Hepatitis B serology, antiphospholipid, beta-2-glycoprotein and anticardiolipin antibodies were negative. The $\mathrm{IgG}_{4}$-related disease was excluded based on clinical presentation and laboratory workup (low IgG levels and normal complement levels). Although the gold standard for diagnosis of vasculitis is biopsy, it was not feasible given the high risk of bleeding. The presumptive diagnosis of polyarteritis nodosa (PAN) was

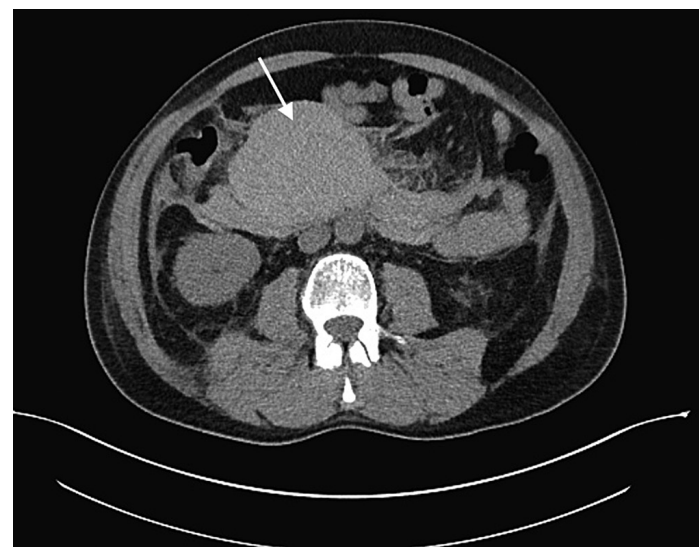

Figure $1 \mathrm{CT}$ abdomen revealing abdominal haematoma (arrow mark), axial view.

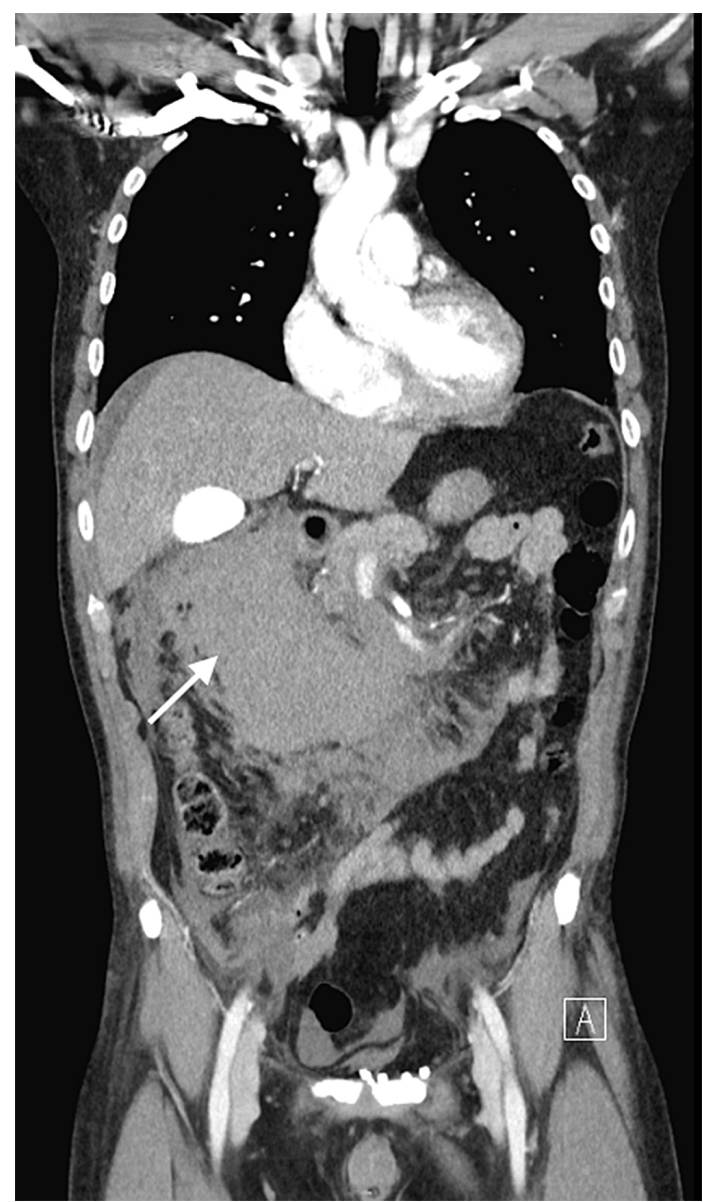

Figure $2 \mathrm{CT}$ abdomen revealing abdominal haematoma (arrow mark), coronal view.

established, and the patient was treated with steroids leading to significant clinical improvement. He was advised to follow up in rheumatology clinic for further treatment.

Retrospectively, our patient did manifest subjective fevers, but no other constitutional symptoms, cutaneous involvement, peripheral neuropathy or classically associated mononeuritis multiplex. Yet, the new-onset hypertension, imaging findings of wedge-shaped renal infarcts without glomerular disease on urinalysis and microaneurysms on abdominal angiograph led to the diagnosis of PAN.

PAN is a necrotising vasculitis of medium-sized arteries manifesting from single organ to polyvisceral involvement, excluding lungs. Inflammation of the arteries may lead to occlusion or rupture, presenting as ischaemia or haemorrhage. ${ }^{1}$ PAN often presents with constitutional features, such 


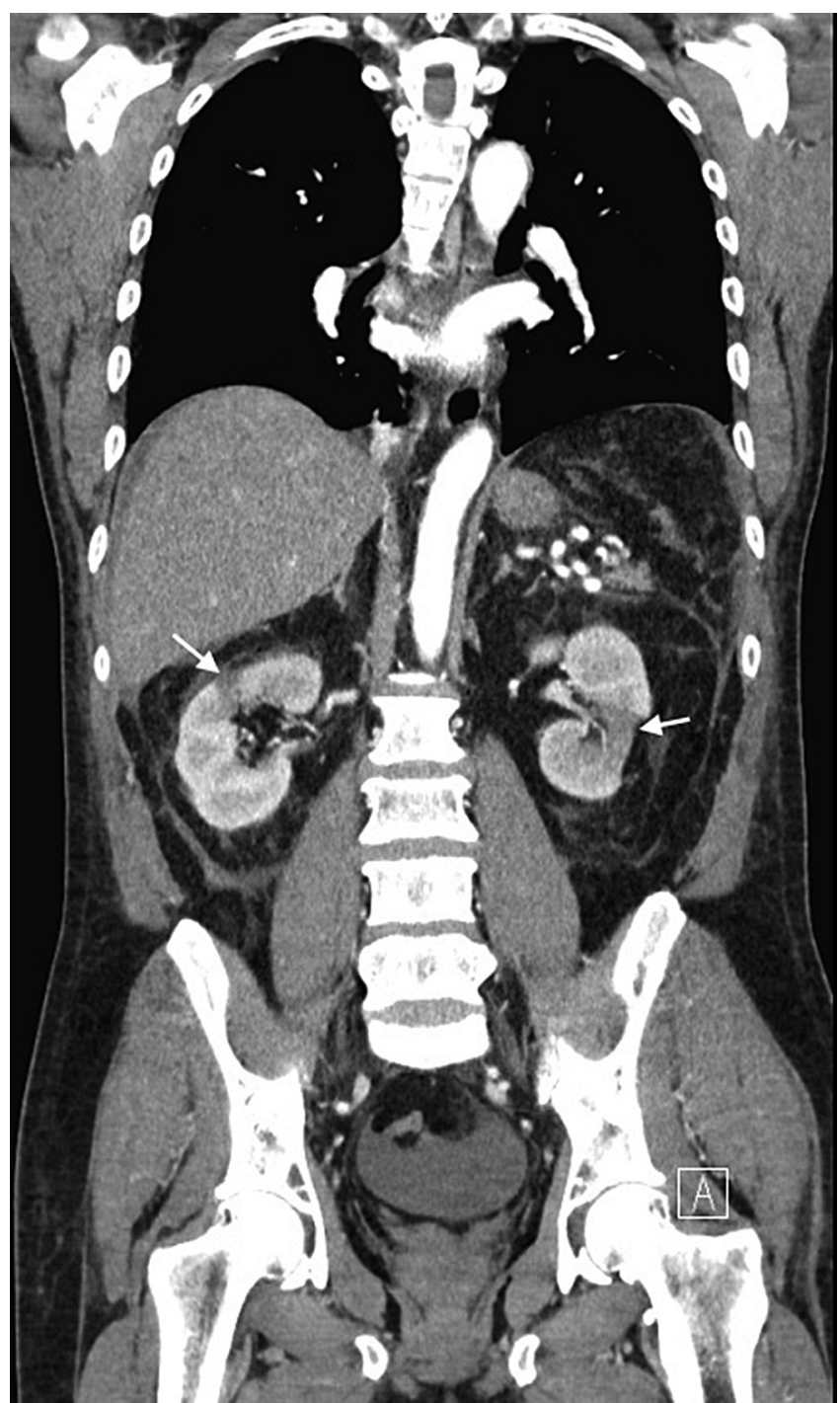

Figure $3 \mathrm{CT}$ abdomen revealing bilateral renal infarcts (arrow marks), coronal view.

as fever, malaise, weight loss and myalgias, which are usually recognised retrospectively. Arthralgias of large joints can occur in up to $50 \%$ of cases. Mononeuritis multiplex is the main neurological sign and occurs in $60 \%$ of patients. ${ }^{2}$ Cutaneous manifestations of PAN are purpura, livedo reticularis, necrotic ulcers or subcutaneous nodules. ${ }^{1}$ Involvement of gastrointestinal tract can present as surgical abdomen in up to one-third of the cases, but these symptoms are challenging to diagnose due to their non-specific nature, requiring mesenteric angiography or surgical exploration. ${ }^{12}$ Involvement of the kidneys can lead to tissue infarction, wedge-shaped infarcts or haematoma from rupture of renal microaneurysms, and renin-mediated hypertension. ${ }^{2}$

The diagnosis of PAN cannot be made by a test or a clinical finding, instead, it is a combination of clinical, angiographic and biopsy findings. Most often, PAN is suspected when constitutional symptoms and multisystem involvement are present with the hallmark of microaneurysms are demonstrated on angiography, even if histological confirmation is absent. ${ }^{1}$

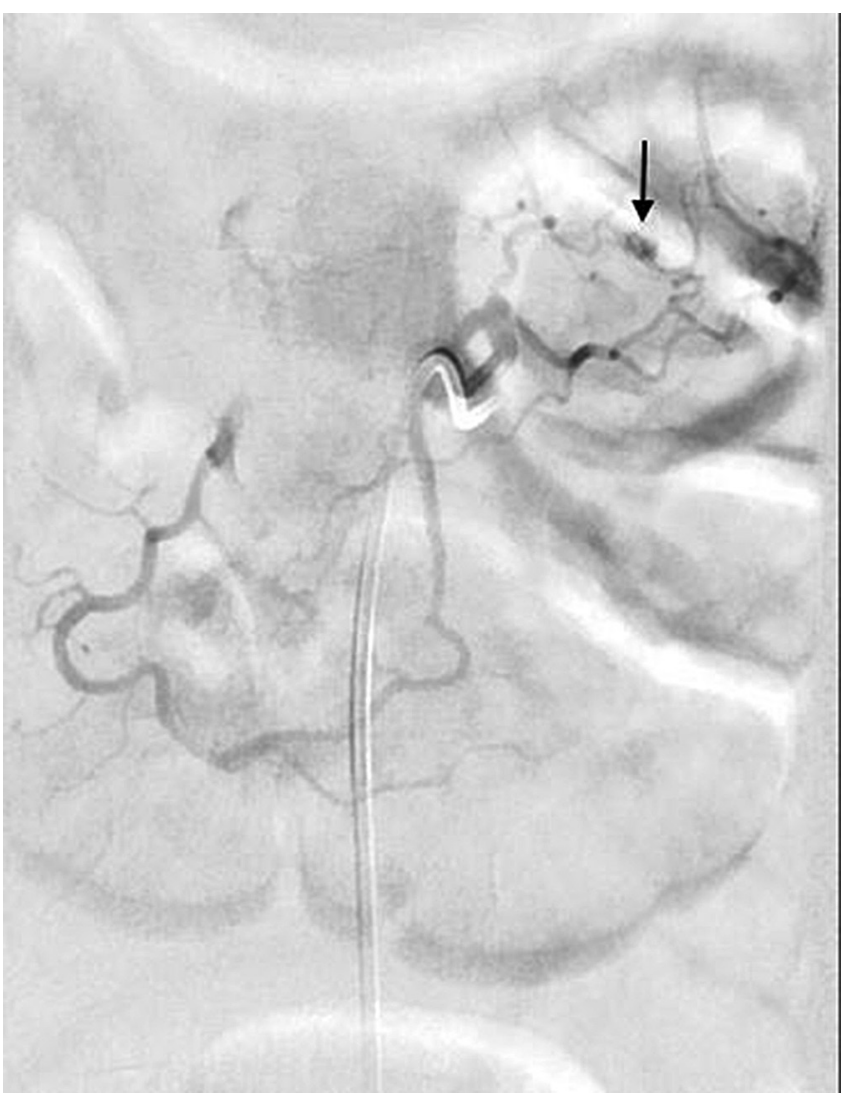

Figure 4 Abdominal angiography demonstrating a microaneurysm (arrow mark).

\section{Learning points}

- Polyarteritis nodosa (PAN) affects medium-sized arteries creating inflammation that results in their occlusion and rupture, leading to ischaemia and haemorrhage, respectively.

- The diagnosis of PAN is a combination of clinical, angiographic and biopsy findings.

- Healthcare professionals must suspect PAN when constitutional symptoms and multisystem involvement are present, with the hallmark of microaneurysms demonstrated on angiography, even if histological confirmation is absent.

Contributors ES: involved in writing the manuscript and completed submission process. KS: involved in managing the patient, writing parts for the final version of the manuscript, and has read and approved the final version submitted. JB: involved in writing parts for the final version of the manuscript, and has read and approved the final version submitted.

Funding The authors have not declared a specific grant for this research from any funding agency in the public, commercial or not-for-profit sectors.

Competing interests None declared.

Patient consent Not required.

Provenance and peer review Not commissioned; externally peer reviewed.

\section{REFERENCES}

1 De Virgilio A, Greco A, Magliulo G, et al. Polyarteritis nodosa: A contemporary overview. Autoimmun Rev 2016:15:564-70

2 Stone JH. Polyarteritis nodosa. JAMA 2002;288:1632-9. 
Copyright 2018 BMJ Publishing Group. All rights reserved. For permission to reuse any of this content visit http://group.bmj.com/group/rights-licensing/permissions.

BMJ Case Report Fellows may re-use this article for personal use and teaching without any further permission.

Become a Fellow of BMJ Case Reports today and you can:

- Submit as many cases as you like

- Enjoy fast sympathetic peer review and rapid publication of accepted articles

Access all the published articles

- Re-use any of the published material for personal use and teaching without further permission

For information on Institutional Fellowships contact consortiasales@bmjgroup.com

Visit casereports.bmj.com for more articles like this and to become a Fellow 